\title{
Characterization of Arsenite Resistant Escherichia coli Isolated from Tubewell Water of Singair, Manikganj, Bangladesh
}

\author{
Santonu Kumar Sanyal, Ram Prosad Chakrabarty, M Anwar Hossain and Munawar Sultana* \\ Department of Microbiology, University of Dhaka, Dhaka 1000, Bangladesh
}

\begin{abstract}
Arsenic is a toxic metalloid present in the natural environment and arsenite is more toxic form than arsenate. Bacterial species have evolved multiple defense mechanisms to tolerate and transform the toxic forms of arsenic. In this study, arsenic contaminated tubewell water ( 90 meter depth with arsenic concentration of $47 \mu \mathrm{g} / \mathrm{l}$ ) was collected from Singair Upazilla under Manikganj District in Bangladesh. Among a total of 17 arsenite resistant bacteria, a lactose fermenting isolate Sn26 showed high resistance to sodium arsenite up to $25 \mathrm{mM}$ under our laboratory conditions. Sn26 possesses arsB gene conferring arsenite transporter pump mediated arsenic resistance, confirmed by PCR and sequencing. PCR and sequencing of 16S rRNA gene (approximately $1450 \mathrm{bp)} \mathrm{confirmed} \mathrm{Sn26} \mathrm{isolate} \mathrm{as} \mathrm{Escherichia} \mathrm{coli.} \mathrm{The} \mathrm{isolate} \mathrm{contained} \mathrm{a} \mathrm{large} \mathrm{plasmid} \mathrm{of}$ $\sim 34 \mathrm{~kb}$. It is necessary to analyze further the affiliation of this single plasmid with high arsenite tolerance.
\end{abstract}

Keywords: Escherichia coli, arsB gene, Plasmid, Arsenite resistance

\section{Introduction}

The contamination of drinking water sources with arsenic (As) poses a potential threat to human health ${ }^{1}$. Inorganic As, including the highly toxic trivalent form [arsenite; As(III)] and less toxic pentavalent As [arsenate; $\mathrm{As}(\mathrm{V})$ ], is associated with increased cancer risk in a number of geographic areas ${ }^{2}$. The toxicity of As is attributed to the substitution of As (V) for phosphate, affinity of As (III) for protein thiol groups, and protein-DNA and DNADNA cross-linking ${ }^{3}$.

Many bacteria exhibit resistance to lethal concentrations of arsenic (greater than $5 \mathrm{mM}$ sodium arsenite) ${ }^{4}$, yet little is known about the genetics involved in As resistance in environmental bacteria. Plasmids have been detected in Rhodococcus sp., Acidiphilium multivorum, Staphylococcus aureus exhibiting high levels of resistance to arsenic species ${ }^{5-7}$. The most wellcharacterized genetic system for resistance to arsenicals is known as the ars operon ${ }^{8}$. According to Environment Protection Agency (EPA), Escherichia coli is used as indicator bacteria due to its ability to grow and persist in natural tropical environments to check the level of contamination and predict potential risks to human health ${ }^{9}$. This organism develops some complex mechanism of resistance in tropical environment for survival and adaptation. Some environmental strains of $E$. coli can change their properties according to different environmental signals such as fluctuation of temperature, $\mathrm{pH}$, osmolarity etc. because they have the ability to carry some genes specific for regulatory proteins and mobile genetic elements such as plasmid and transposon ${ }^{10}$. In the well-studied ars-containing plasmid
R773 (491 kbp), isolated from E. coli, the operon consists of five genes that are controlled from a single promoter located upstream of the first cistron $(\operatorname{ars} R)^{11}$. These cistrons, $\operatorname{ars} R D A B C$ (in that order), encode an arsenic-inducible repressor ( $\operatorname{ars} R$ ), a negative regulatory protein that controls the upper level of transcription ( $\operatorname{ars} D$ ), an ATPase plus membrane-located arsenite efflux pump (ars $A$ and $\operatorname{ars} B$, respectively) and an arsenate reductase $(\operatorname{ars} C)^{12}$.

Therefore, the central hypothesis of the present study is that $E$. coli adapted in arsenic polluted environment of Bangladesh might have developed resistance to arsenic and might possess inherent mechanism to resist this toxic metalloid.

\section{Materials and Methods}

Isolation of arsenite resistant presumptive Escherichia coli

Ground water sample (SNGW-1) was collected from the Tubewell (90 m depth) of Madhabpur Union Parishad under Singair Upazilla Manikganj District of Bangladesh. A $100 \mu \mathrm{l}$ of sample was directly spread onto minimal salts enrichment agar [2\% (w/v)] medium described previously ${ }^{13}$ supplemented with sodium arsenite, $\mathrm{NaAsO}_{2}(2 \mathrm{mM})$. From 17 colonies, Gram-negative colonies were selected from the arsenite supplemented media and subcultured onto MacConkey agar to differentiate lactose fermenter from nonlactose fermenter. Lactose fermenting pink colonies from MacConkey agar was further subcultured on eosine methylene blue (EMB) agar to detect the presence of presumptive Escherichia coli in our studied sample. One of the isolate Sn26 was selected for further investigation.

*Corresponding author:

Munawar Sultana, Department of Microbiology, University of Dhaka, Dhaka 1000, Bangladesh

Tel: +880 (02) 9661920; E-mail: munawar@du.ac.bd 


\section{Minimum inhibitory concentration (MIC) of arsenite}

To determine the level of minimum inhibitory concentration (MIC) of As (III) of selected isolate Sn26, each well of a 96-well microtiter plate was filled with 130 ìl sterile minimal salt medium (MSM) (described above) and supplemented with $\mathrm{NaAsO}_{2}$ to achieve different concentrations of As (III) (0, 2, 4, 6, 8, 10, 12, 15, 18, 20, $25,27,30 \mathrm{mM}$ ). Isolate $\mathrm{Sn} 26$ was grown in $5 \mathrm{ml}$ of its respective MSM without arsenic for $48-72 \mathrm{~h}$ at $28 \pm 2^{\circ} \mathrm{C}$ on a rotary shaker (150 rpm). Twenty microliter of bacterial inoculum $\left(\mathrm{OD}_{600}=0.1\right)$ was placed in each respective well. One well of each row was set as negative control (respective medium only). Initial cell density and bacterial growth after $24 \mathrm{~h}$ were measured using EZ Read 400 Microplate Reader (Biochrom) at $600 \mathrm{~nm}$. To assess the statistical validity and reproducibility of the experiment OD values at 600 nm were taken in triplicate.

\section{DNA extraction}

DNA of isolate Sn26 was extracted with ATP $^{\text {TM }}$ Genomic DNA Mini Kit (ATP Biotech Inc, USA) according to the kits manual and the chromosomal DNA was stored at $-20^{\circ} \mathrm{C}$.

PCR amplification of arsenic resistance arsB and 16S rRNA gene

One set of degenerate primers darsB1F/darsB1R (dars B1F:5'GGTGTGGAACATCGTCTGGAAYGCNAC-3 darsB1R: 5CAGGCCGTACACCACCAGRTACATNCC-3) ${ }^{15}$ and $16 \mathrm{~S}$ rRNA gene specific primers (27F: AGAGTTTGATCCTGGCTCAG and 1492R: 5-GGTTACCTTGTTACGACTT-3) ${ }^{14}$, were used for the detection of arsenite resistance gene ( $\operatorname{ars} B)$ and molecular identification of the isolate Sn26 respectively.PCR reaction mixtures contained approximately 50 ng DNA template, 1 x PCR buffer, $0.2 \mathrm{mM}$ of each deoxyribonucleoside triphosphates, 0.2 $\mathrm{m} M$ of each primer and $1 \mathrm{U}$ Taq DNA polymerase in $25 \mu \mathrm{l}$ reaction mix. The PCR reaction condition was an initial denaturation step ( $94^{\circ} \mathrm{C}$ for $3 \mathrm{~min}$ ) followed by 35 cycles of $94^{\circ} \mathrm{C}$ for $30 \mathrm{~s}, 55^{\circ} \mathrm{C}$ for 30 $\mathrm{s}$, and $72^{\circ} \mathrm{C}$ for $30 \mathrm{~s}$. Negative control included a deionized water reagent control. The amplified products were separated on a Trisacetate-EDTA (TAE)-1\% agarose gel ( $0.5 \mu$ g of ethidium bromide per $\mathrm{ml}$ ) by electrophoresis. The bands were visualized on a UV transilluminator (Alphaimager HP, USA).

\section{Sequencing and phylogenetic analysis}

Amplified arsenite resistance ( $\operatorname{ars} B$ ) and 16S rRNA gene from selected isolates were purified by Wizard PCR SV Gel and PCR Clean-Up System kit (Promega, USA) according to the manual instructions. Purified PCR products were sequenced on an ABI sequencer (ABI Prism 3130 Genetic Analyzer, USA) using specific primers. The sequences were compared to the entire GenBank nucleotide databases. Phylogenetic analysis of arsB and 16S rRNA gene sequences was performed using MEGA software ${ }^{16}$. The maximum likelihood distance method based on Tamura 3 parameter was used to construct phylogenetic trees and the validity of the branches was determined with 1,000 bootstrap replicates.

\section{Plasmid profiling}

Plasmid DNA was extracted by using Wizard ${ }^{\circledR}$ Plus SV Minipreps plasmid DNA Purification kit (Promega, USA) and by manual extraction procedure ${ }^{17}$. Plasmid DNA was analyzed by electrophoresis in $0.8 \%$ agarose gel. Plasmids extracted from $E$. coli $\mathrm{V}_{517}$ were used as control and for molecular weight determination.

\section{Results}

Cultural and microscopic observation of isolate Sn26

From 17 colonies on minimal salts agar medium containing $2 \mathrm{mM}$ arsenite, microscopic observation was done and 5 Gram-negative colonies were selected for subculture onto selective MacConkey agar and eosine methylene blue (EMB) agar medium. Only one isolate Sn26 produced pink colonies (characteristic of lactose fermenter) on MacConkey agar medium and also showed metallic sheen on EMB agar and was presumptively identified as E. coli.

High MIC of arsenite of isolate Sn26

Lactose fermenting presumptively identified E. coli Sn26 was selected for determination of MIC of arsenite on respective heterotrophic MSM medium. Isolate Sn26 was able to multiply very rapidly up to $8 \mathrm{mM}$ (viable count $=9.69 \times 10^{8}$ cells $/ \mathrm{ml}$ ) concentration of $\mathrm{NaAsO}_{2}$ but its OD reduced to rapidly when supplemented $\mathrm{NaAsO}_{2}$ concentration increased to $10 \mathrm{mM}$ (viable count $=5.28 \times 10^{8}$ cells $/ \mathrm{ml}$ ) and the bacterium can survive up to 25 $\mathrm{m} M$ after 48 hours of incubation but rate of multiplication reduced significantly. The $\mathrm{MIC}$ of $\mathrm{NaAsO}_{2}$ for the isolate was detected as $27 \mathrm{~m} M$ (Figure 1).

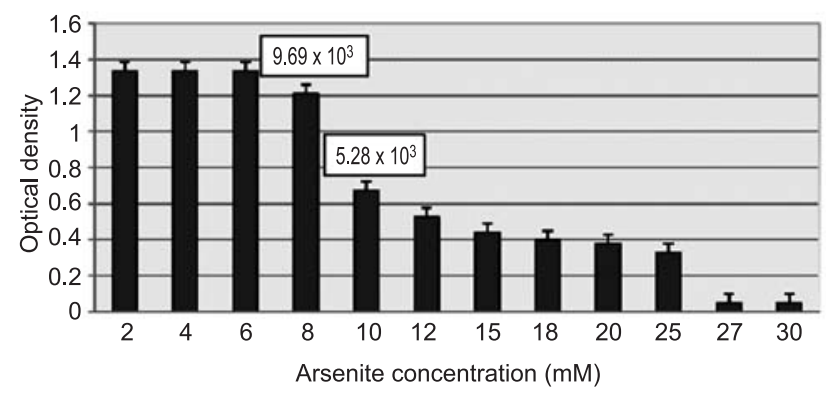

Figure 1. A bar representation showing optical density at $600 \mathrm{~nm}$ wavelength (X-axis) of Sn26 at different concentraions of supplemented arsenite (Y-axis). Error bars have been made by using standard deviation. Standard deviation is calculated from the mean of triplicate results.

\section{PCR amplification and phylogeny of arsB gene}

High arsenite resistance within the isolate Sn26 might be due to the presence of arsenite resistance gene (ars). To ensure this, arsB gene specific PCR was performed and positive specific amplicon (750bp) was obtained (Figure 2a). After sequencing 


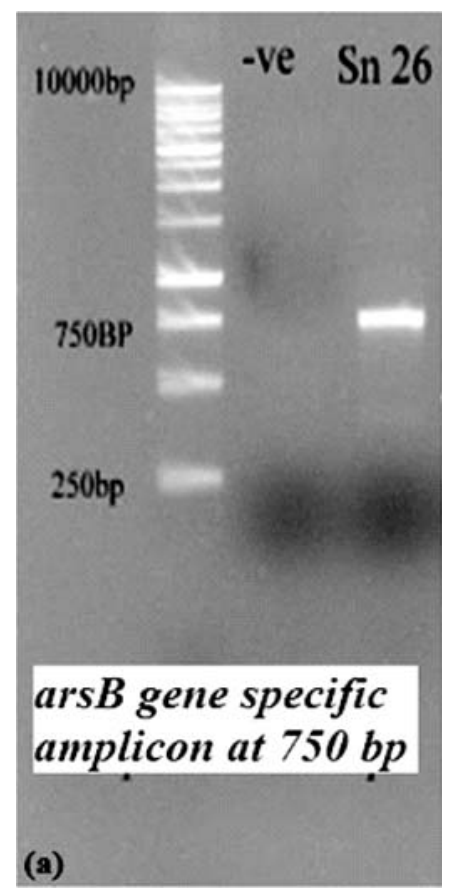

Figure 2. (a) Arsenite efflux pump specific amplicon of Sn26 at 750bp (b) Phylogenetic tree of arsenite efflux pump specific protein ArsB where Sn26 arsenite efflux pump specific protein (KM373345 in bold) closely clustered with other Escherichia coli ArsB protein. The tree was calculated from deduced amino acid sequences aligned in programClastalX. The tree was generated in program MEGA 5 using the Neighbour-Joining algorithm. Bootstrap value ( $n=1,000$ replicates).

and nucleotide BLAST search, the arsB sequence of Sn26 showed 99\% homology to the arsenite efflux pump specific protein of $E$. coli strain 87-14 (WP_032192172). The arsB gene sequence was submitted to NCBI database under the accession number KM373345.

The $\operatorname{ars} B$ sequence of the isolate $\mathrm{Sn} 26$ and other close relative reference sequences retrieved from database were aligned using Clustal W following translating into amino acid sequences and showed good correlation to the conserved regions. Phylogenetic analysis of Sn26 amino acid sequences showed that it is closely clustered with $E$. coli arsenical pump specific protein (Figure 2b). But it showed divergence when compared with reference strain Herminiimonas arsenicoxydans arsenical pump specific protein (Figure 2b).

Molecular identification and phylogenetic analysis

Sequencing of purified product of $16 S$ PCR of Sn26 showed that the isolate has $100 \%$ similarity with $E$. coli through BLAST search. After construction of phylogenetic tree, it was found that our isolate was homologous with the sequences of other environmental E. coli isolates (Figure 3). The 16S rRNA gene sequence of Sn26 was deposited in NCBI GenBank under accession number KM373319.

Plasmid profile analysis of E. coli Sn26

Previous report suggested that arsenite efflux pump (arsB) protein specific resistance may be chromosomal or mediated by mobile genetic elements such as plasmid and transposon. Within the high arsenite resistant isolate Sn26, only one plasmid with 434 kbp size was retrieved by the plasmid purification process (Figure 4) and that plasmid was gel purified for further analysis. PCR of gel purified plasmid was performed targeting arsB gene. After agarose gel electrophoresis, ars $B$ gene specific band was detected at 750 bp position which was again confirmed by respective sequencing of the PCR product. Further hybridization of the plasmid and chromosomal DNA of the isolate and molecular probing is necessary to determine the possibility of plasmid mediated mechanism of resistance within the isolate. 


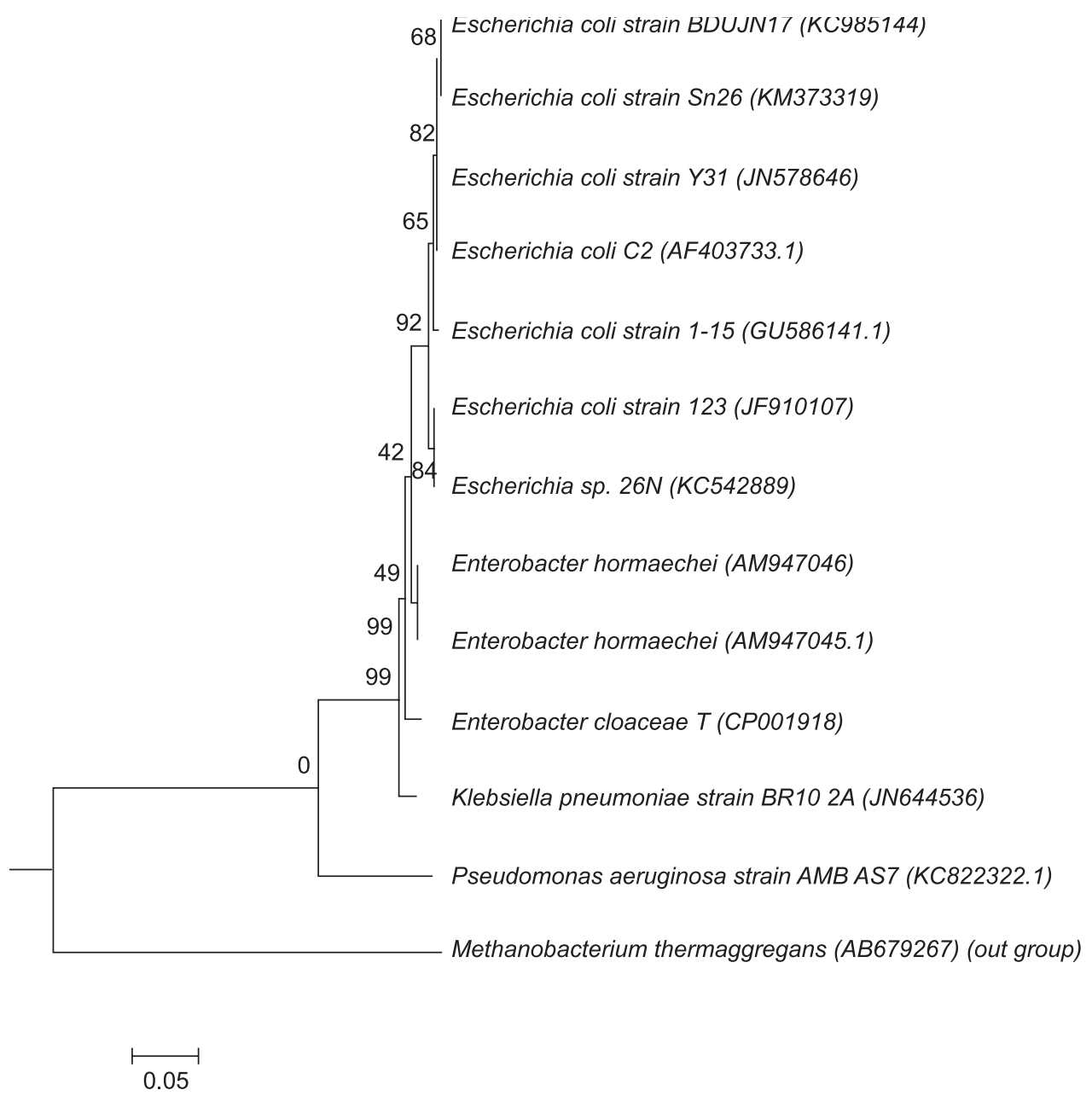

Figure 3. Phylogenetic tree of $16 S$ rRNA gene sequence of Sn26 (KM373319) isolated ground water sample and close relative reference isolates retrieved from database with accession numbers. The tree was generated in program MEGA 5 using the NeighbourJoining algorithm- with the Methanobacterium sequence served as out group.

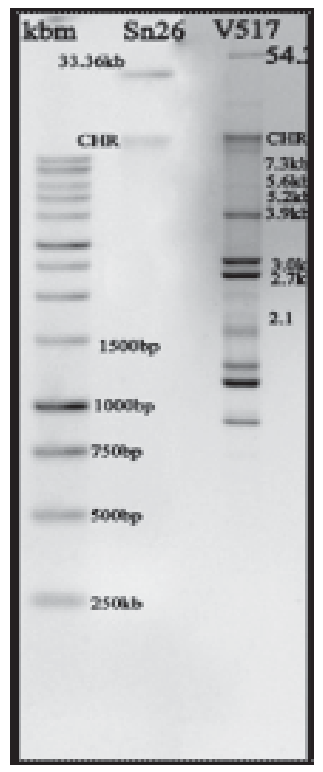

Figure 4. Plasmid profile of Sn26 showing presence of a large plasmid ( $34 \mathrm{kbp}$ ) where Escherichia coli strain $V_{517}$ was used as markers for molecular weight and $1 \mathrm{~kb}$ ladder for identification of plasmid size.

\section{Discussion}

In our study ars $B$ gene, which encodes membrane-located arsenite efflux pump, has been detected within high arsenite resistant isolate E. coli Sn26, isolated from tubewell water sample of Singair, Manikganj in Bangladesh. The isolate Sn26 was retrieved from a tubewell water where total arsenic concentration was detected as $47 \mu \mathrm{g} / \mathrm{l}$ (above the international standard for permissible level of arsenic in drinking water) ${ }^{18}$. The presence of high level of arsenic in groundwater which may impart selective pressure for evolution of arsenic resistant bacterial species more specifically thrive of arsenic resistant genes for adaptation and survival of bacteria in the As polluted areas ${ }^{15}$.

The ars operon is the most-well-characterized genetic system responsible for arsenic resistance ${ }^{19}$. The ars operon functions as a detoxification mechanism by lowering the intracellular arsenic concentration, thus conferring resistance to $\mathrm{As}(\mathrm{V})$ and $\mathrm{As}(\mathrm{III})^{11}$. The detection of arsenite efflux pump encoding gene in our studied isolate Sn26 revealed molecular evidence of its high arsenite resistance and this data was well corroborated with other studies $^{5}$. It has already been reported that in the $E$. coli, plasmid 773 ars operon contains five genes ( $\operatorname{ars} R D A B C$ ) where $\operatorname{ars} B$ 
encoding an arsenite-stimulated ATPase pump specific protein. In addition, $\mathrm{As}^{\mathrm{r}}$ (arsenic resistance) loci have also been found on the chromosomes of Pseudomonas aeruginosa ${ }^{6}$. Approximately $35 \mathrm{kbp}$ longer single plasmid was detected in isolate Sn26 and detection of arsB gene by PCR indicate that the high arsenite resistance of isolate Sn26 might be attributed to the presence of this plasmid.

The present study inferred the following insights: (i) Escherichia coli Sn26 is adapted in the arsenic polluted drinking water and harboring genetic determinants of arsenic resistance, and (ii) presence of plasmid and PCR based detection of arsB gene in that plasmid indicated the involvement of mobile genetic elements conferring arsenite resistance. Hybridization of the plasmid and chromosomal DNA of the isolate and molecular probing is necessary to confirm the plasmid mediated mechanism of arsenite resistance within the isolate.

\section{Acknowledgement}

The study was funded by University Grant Commission (UGC) and Bangladesh Council of Scientific and Industrial Research (BCSIR).

\section{References}

1. Nriagu JO. 2002. Arsenic poisoning through the ages. In Environmental Chemistry of Arsenic (Frankenberger Jr ET ed), pp 1-26. Marcel Dekker, Inc., New York.

2. Neubauer O. 1947. Arsenical cancer: A review. Br J Cancer. 1(2): 192-251.

3. Hughes MF. 2002. Arsenic toxicity and potential mechanisms of action. Toxicol Lett. 133: 16.

4. Cavalca L, Corsini A, Zaccheo P, Andreoni V and Muyzer G. 2013. Microbial transformations of arsenic: Perspectives for biological removal of arsenic from water. Future Microbiol. 8(6): 753-768.

5. Suzuki K, Wakao N, Kimura T, Sakka K and Ohmiya K. 1998. Expression and regulation of the arsenic resistance operon of Acidiphilium multivorum AIU 301 plasmid pKW301 in Escherichia coli. Appl Environ Microb. 64(2): 411-418.

6. Saltikov CW and Olson BH. 2002. Homology of Escherichia coli R773 $\operatorname{ars} A$, $\operatorname{ars} B$, and $\operatorname{ars} C$ genes in arsenic-resistant bacteria isolated from raw sewage and arsenic-enriched creek waters. Appl Environ Microb. 68(1): 280-288.
7. Silver S, Budd K, Leahy KM, Shaw WV, Hammond D, Novick RP, Willsky GR, Malamy MH and Rosenberg H. 1981. Inducible plasmiddetermined resistance to arsenate, arsenite, and antimony (III) in escherichia coli and Staphylococcus aureus. J Bacteriol. 146(3): 983-996.

8. Silver S and Phung LT. 2005. Genes and enzymes involved in bacterial oxidation and reduction of inorganic arsenic. Appl Environ Microb. 71(2): 599.

9. Wheeler Alm E, Burke J and Spain A. 2003. Fecal indicator bacteria are abundant in wet sand at freshwater beaches. Water Research. 37(16): 3978-3982.

10. Hayashi T, Makino K, Ohnishi M, Kurokawa K, Ishii K, Yokoyama K and Shinagawa H. 2001. Complete genome sequence of enterohemorrhagic Eschelichia coli O157:H7 and genomic comparison with a laboratory strain K-12. DNA Research. 8(1): 11-22.

11. Carlin A, Shi W, Dey S and Rosen BP. 1995. The ars operon of Escherichia coli confers arsenical and antimonial resistance. $J$ Bacteriol. 177(4): 981-986.

12. Diorio C, Cai J, Marmor J, Shinder R and DuBow MS. 1995. An Escherichia coli chromosomal ars operon homolog is functional in arsenic detoxification and is conserved in Gram-negative bacteria. $J$ Bacteriol. 177(8): 2050-2056.

13. Santini JM and vanden Hoven RN. 2004. Molybdenum-containing arsenite oxidase of the chemolithoautotrophic arsenite oxidizer NT26.J Bacteriol. 186(6): 1614-1619.

14. Weisburg WG, Barns SM, Pelletier DA and Lane DJ. 1991. 16S ribosomal DNA amplification for phylogenetic study. $J$ Bacteriol. 173(2): 697-703.

15. Achour AR, Bauda P and Billard P. 2007. Diversity of arsenite transporter genes from arsenic-resistant soil bacteria. Res Microbiol. 158(2):128-137.

16. Tamura K, Peterson D, Peterson N, Stecher G, Nei M and Kumar S. 2011. MEGA5: Molecular evolutionary genetics analysis using maximum likelihood, evolutionary distance, and maximum parsimony methods. Mol Biol Evol. 28(10): 2731-2739.

17. Bimboim H and Doly J. 1979. A rapid alkaline extraction procedure for screening recombinant plasmid DNA. Nucleic Acids Res. 7(6): 1513-1523.

18. APHA. 2005. Standard Methods for the Examination of Water and Wastewater, 21 $1^{\text {st }}$ edn). American Water Works Association and Water Environment Federation (APHA), American Public Health Association, Washington DC.

19. Saltikov CW, Cifuentes A, Venkateswaran K and Newman D. K.2003. The ars detoxification system is advantageous but not required for $\mathrm{As}(\mathrm{V})$ respiration by the genetically tractable Shewanella species strain ANA-3. Appl Environ Microb. 69(5): 2800-2809. 